\title{
Diesel degrading potential of bacterial strains present in petroleum contaminated soils
}

\author{
KMA Karunathilaka and P Samaraweera
}

\section{Introduction}

Anthropogenic activities have caused an accumulation of hydrocarbon pollutants in the environment. Bioremediation is a cost-effective remediation method that can degrade petroleum pollutants without disrupting delicate ecosystems. The bacterial strains on petroleum contaminated soils are vastly exposed to hydrocarbons resulting in an increase in naturally occurring petroleum degraders. The objectives of the current study were to isolate and investigate the diesel degrading ability of such bacterial strains and to identify and store potent petroleum degraders that could become potential bioremediation agents.

\section{Methods}

The soil suspensions were inoculated into sterile Bushnell Haas broth containing diesel and Tween20 (BHDT) and incubated for 7 days at $37{ }^{\circ} \mathrm{C}$ on a shaker. BHDT agar streak plates were made from these broths to isolate single colonies. The different strains were isolated based on morphological and biochemical tests. The degrading abilities of these isolated strains were determined using three assays. In turbidity assay, the bacterial inoculums were introduced to BHDT broth and incubated for 10 days at $37^{\circ} \mathrm{C}$ on a shaker and the $\mathrm{OD}_{600 \mathrm{~nm}}$ measurements were taken. To perform the 2,6-Dichlorophenolindophenol (DCPIP) assay, to the BHDT broth supplemented with DCPIP, the bacterial inoculums were added and incubated at $37^{\circ} \mathrm{C}$ on a shaker to observe the color change. Finally, BH agar plates overlaid with diesel emulation was used for the $\mathrm{BH}$ plate assay and the diameters of the colonies were measured after seven days. The potent degraders were identified by 16 s rRNA sequencing.

\section{Results}

Twenty five soil samples were collected and from these samples seventeen potential stains were identified based on their morphological differences and further confirmed as different strains using biochemical tests. Based on the three biodegradation assays, five potent diesel degrading bacterial strains were identified. Determination of the nucleotide sequence of the 16S rRNA gene of the five highest degraders showed that four of the species belonged to the genus Alcaligenes and the other belonged to the genus Staphylococcus.

\section{Conclusions}

The isolated bacterial strains from the contaminated soils were able to utilize diesel as the sole carbon source while growing on a minimal medium. Previous studies have shown that bacterial strains belonging to the genus Alcaligenes and Staphylococcus are capable of degrading petroleum oil, supporting the findings of this study. Further studies should be conducted to quantify the amount of diesel degraded by the individual strains.

Keywords: Bioremediation, Biodegradation, BH-plate assay, DCPIP assay, 16S rRNA gene sequencing

Department of Department of Molecular Biology and Biotechnology, Faculty of Science, University of Peradeniya, Sri Lanka

Address for correspondence: KMA Karunathilaka. Telephone:+94750502759 Email: amzkaru123@gmail.com (iD https://orcid.org/0000-0003-1329-7512 